\title{
Study on Employment Ability of Economics and Management Graduates in Agricultural and Forestry Universities
}

\author{
Hong $\operatorname{Pan}^{1}$ \\ ${ }^{1}$ College of Economics and Management, Sichuan Agricultural University, Chengdu, China \\ Correspondence: Hong Pan, College of Economics and Management, Sichuan Agricultural University, Chengdu \\ 611130, Sichuan, China. E-mail: panhong780@126.com
}

Received: August 4, 2012 Accepted: September 2, 2012 Online Published: November 30, 2012

doi:10.5539/ass.v8n15p115 URL: http://dx.doi.org/10.5539/ass.v8n15p115

\begin{abstract}
Given the data of employment of 2012 economics and management graduates in Sichuan Agricultural University, this article makes a statistical analysis of students' employment concept, employment status quo and conditions and problems in occupational planning and further determines necessary core competitive strength for economics and management graduates in agricultural and forestry universities.
\end{abstract}

Keywords: agricultural and forestry universities, economics and management, employment

The issue of employment among university students has been a focus of the society, especially after the continuous attack by the international economic situation in the recent four years. Yet, the current labor force demand behavior is based on "job qualification model with an analysis of occupations", and it is through price mechanism that appropriate talents are selected in the labor force market. Among the large army of job hunting with a cloud of master hands, it deserves our reflection and improvement in our work how to let university students who have just graduated from the university stand out, adapt gto the selection standard of the society and find an occupational path that is suitable for themselves as soon as possible.

As the subject in employment, university students' employment concept has a direct effect on their selection of an occupation and selection of employment area, which further influences the employment issue of university students. This survey is aimed to know about the employment concept, employment status quo and conditions and problems existing in the process of selecting a job among economics and management graduates in agricultural and forestry universities, further have an idea about the necessary core competitive strength for economics and management graduates in agricultural and forestry universities, better improve the vocational counseling and occupational career planning and make an adjustment on the quality and direction of capacity cultivation of those who have not yet graduated so as to adapt to the requirements of the contemporary society.

\section{Survey Form and Recovery of Questionnaire}

This survey employs the method of questionnaire survey and makes a sampling survey. The respondents are the 2012 graduates majoring in economics and management in agricultural and forestry university. Altogether, 420 questionnaires were released and 361 questionnaires were recovered, among which 340 questionnaires were qualified and the passing rate was $80.95 \%$. In the sample, there are 170 male students and 170 female students, which respectively account for 50\%. We use EXCEL to make a statistical analysis on the data of the sample.

\section{An Analysis of the Survey Result}

Generally speaking, a large majority of graduates are from Sichuan Province, and the cities and most of them work in cities within Sichuan Province, mostly in Chengdu and the surrounding areas. The territorial scope of employment for graduates is relatively narrow and is confined to Sichuan. Graduates have no extensive communication with the external world and their working units are mostly bank institutions and enterprises and public institutions.

\subsection{An Analysis of the Employment Status Quo}

We can get from an analysis of the job satisfaction that, almost $80 \%$ of graduates are relatively satisfied with their jobs and most of their judgment on satisfaction with the employment positions focuses on the development prospect of the employment, a large economic income and perfect interpersonal relationship. 
As is shown in Figure 1, graduates who are satisfied with their current job account for $28 \%$ of the total, who are relatively satisfied with their job account for $54 \%$, who are not satisfied with their current job account for $11 \%$ and who have no clear idea about whether they are satisfied with their job account for $7 \%$.

As is shown in Figure 2, there are $67.47 \%$ of graduates who attach great importance to the development prospect of their career, $30.42 \%$ of graduates who relatively focus on their development prospect and the two add up to $97.89 \%$. There are $33.33 \%$ of graduates who attach great importance to the economic income of their job, $62.46 \%$ of graduates who relatively focus on their economic income and the two add up to $95.79 \%$. There are $40.06 \%$ of graduates who attach great importance to their interpersonal relationship, $54.6 \%$ of graduates who relatively focus on their interpersonal relationship and the two add up to $94.66 \%$.

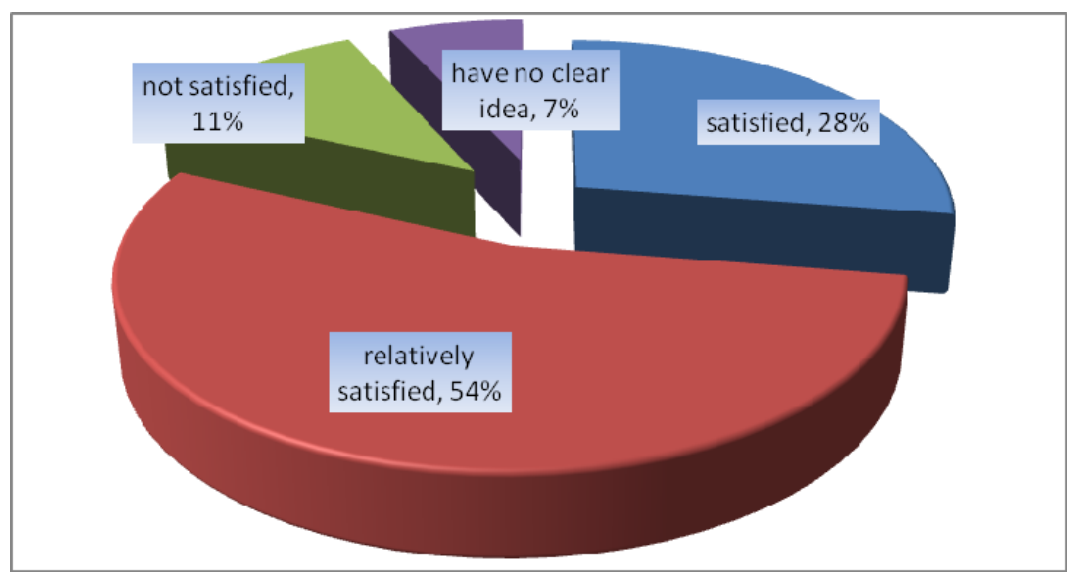

Figure 1. An analysis of satisfaction with employment

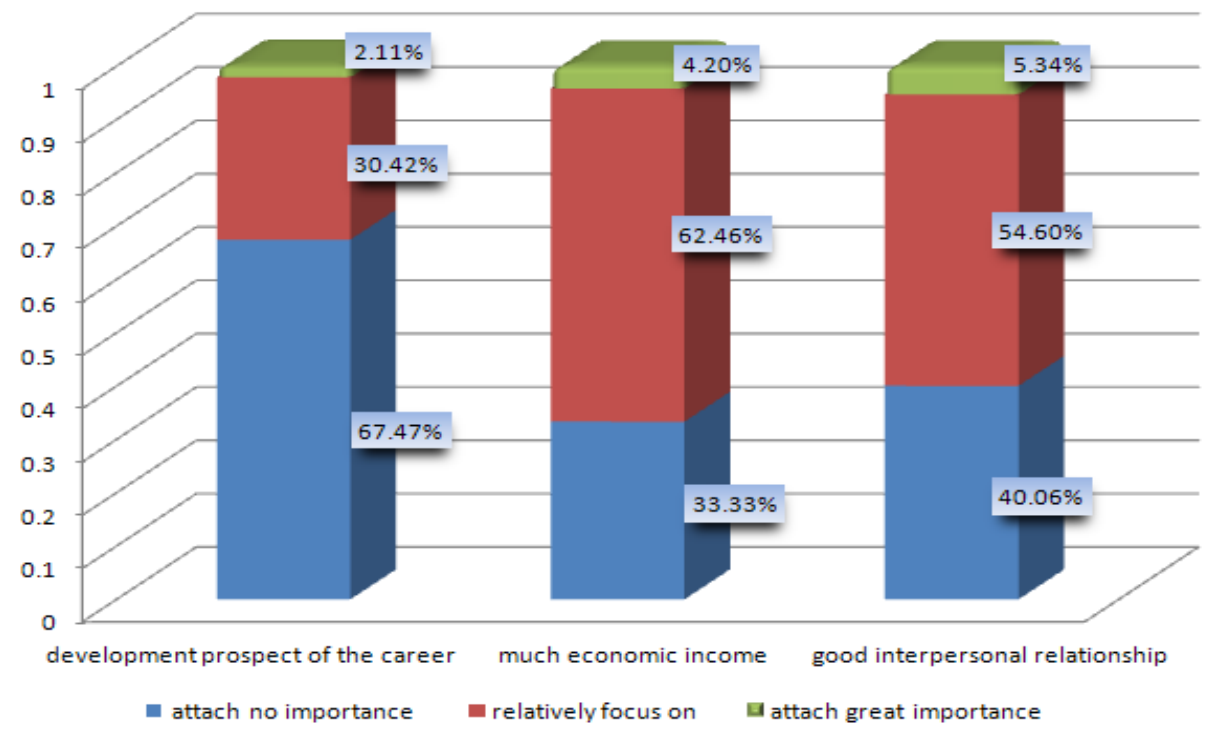

Figure 2. An analysis of specific reasons in evaluation of job satisfaction

A large majority of graduates focus on the development prospect of their career and are concerned about their development prospect of their job and the development direction in the future. At the same time, the economic income and the interpersonal relationship are also importance factors that affect graduates' satisfaction with their job. The key to whether there is a development prospect in the career is whether the quality and capacity of graduates suit with themselves, which requires the graduates to concentrate more on enhancing their accomplishment, learn to actively get well with others and place themselves in a harmonious and healthy social relationship instead of self-reclusion.

\subsection{An Analysis of the Employment Concept}

In selection of employment by graduates, professional counterpart is still a focus of consideration for an 
employment and the university of graduation, educational background and speciality are also main factors that affect students' successful employment.

As is shown in Figure 3, there are $12 \%$ graduates who see professional counterparts as quite important, $54 \%$ of graduates who believe professional counterparts as relatively important and the two add up to $66 \%$. There are $32 \%$ of graduates who see professional counterparts as not much important and there are merely $2 \%$ of graduates who have no clear idea. As is shown in Figure 4, among the main factors that affect the successful employment, the proportion of graduates who see the reputation of the university as quite important, very important and relatively important is respectively $15.07 \%, 31.88 \%$ \& $42.03 \%$, with a total of $88.98 \%$. Those who believe that the educational background is important account for a proportion of $95.76 \%$ and those who believe that speciality is important account for a proportion of $91.59 \%$.

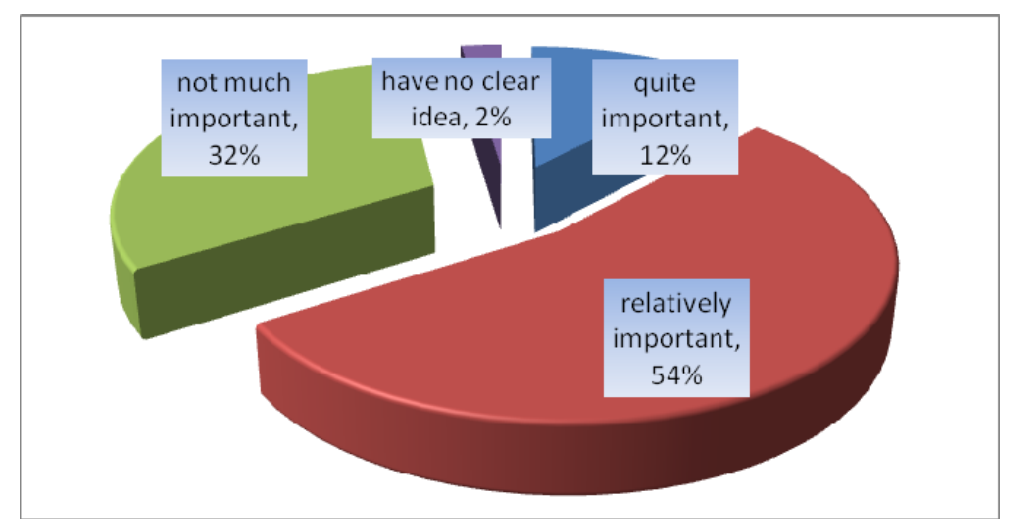

Figure 3. Selection of an occupatioin considering professional counterparts

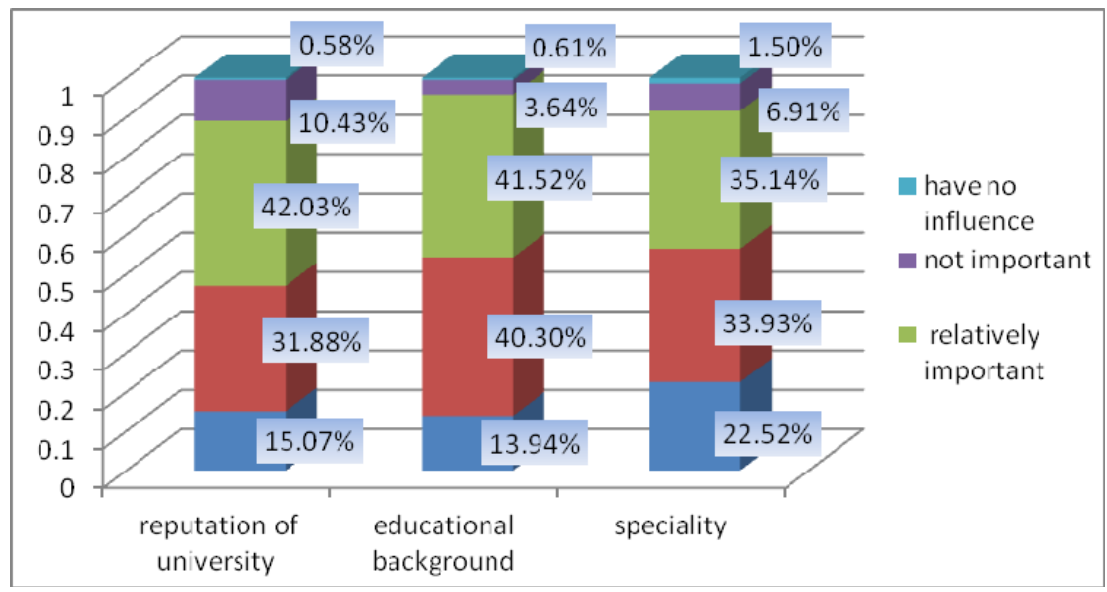

Figure 4. An analysis of factors in a successful employment

It is indicated by the statistical analysis that $70 \%$ of graduates still attach great importance to the professional counterparts and in the eyes of these graduates, only when their profession suits with their job, can their career get better development. Nevertheless, we should note that there are still almost $30 \%$ of graduates who believe that profession is not much important. This also indicates from another perspective that, the university students ought to cultivate their all-around quality, enhance their adaptability to changes and cultivate themselves as an inter-disciplinary talent.

At the same time, it is generally believed by graduates that university, educational background and speciality have great influences upon successful employment. Graduates believe that speciality is of great importance to successful employment and this requires the university students to continuously cultivate their own speciality. The "211 Project" of the state key universities offers perfect learning and growth environment for university students, which is quite favorable for cultivation of university students' capacity.

\subsection{An Analysis of Employment Problems}

It is believed by a large majority of university students that lack of social experience, employment capacity and employment information is the primary problem encountered in the process of employment. As is analyzed in Figure 5, those graduates who believe that lack of social experience and employment capacity and deficiency of 
information is the primary problem in employment respectively account for $28 \%$, those who believe that professional un-counterpart or narrow professional scope is the primary problem account for $20 \%$, those who believe that lack of social relationship makes it difficult to find a job account for $18 \%$ and still $6 \%$ of graduates who believe that gender discrimination exists.

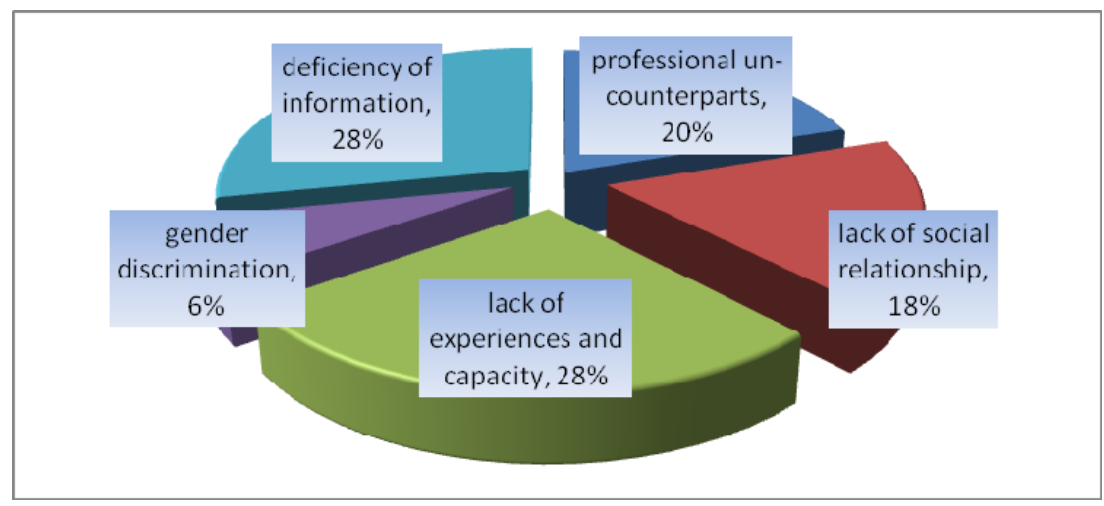

Figure 5. An analysis of problems encountered in the process of employment

Difficulties encountered in the process of employment are various. The above analysis shows that, problems encountered in the process of employment are mainly experience and information. In addition to strengthening the automatic learning capacity of students, the university should also enhance graduates' problem solving ability, strengthen announcement and dissemination of employment information and offer more employment information with professional counterparts. Such employment problems as deficiency of social relationship and gender discrimination will be gradually mitigated with improvement of students' comprehensive quality.

\subsection{An Analysis of Occupational Planning}

The statistical result shows that a large part of graduates have a high job satisfaction and more than half of graduates choose to continue their former job. A specific and clear occupational planning is of great importance to a university student. However, the statistical result shows that $60 \%$ of university graduates have an ambiguous planning on their occupation and their occupational target is not clear.

As is shown in Figure 6, there are 52\% of graduates who wish to continue to try their best in the former position, $20 \%$ of graduates who are prepared for a job-hopping, $3 \%$ of graduates who have the plan for self-employment to start a business, $15 \%$ of graduates who plan to pursue further study and still $4 \%$ of graduates who have no clear plan. It is shown in Figure 7 that, there are 32\% of graduates who have an explicit occupational planning, $59 \%$ of graduates who have an undefined planning and $10 \%$ of graduates who plan to take things one step.

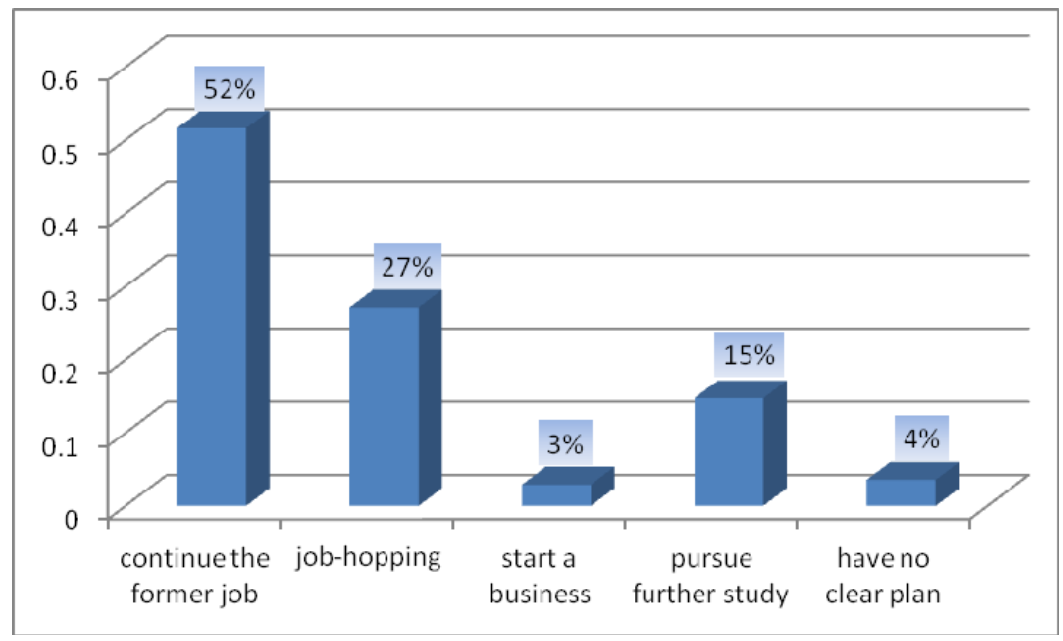

Figure 6. An analysis of planning of graduates for a short-term period 


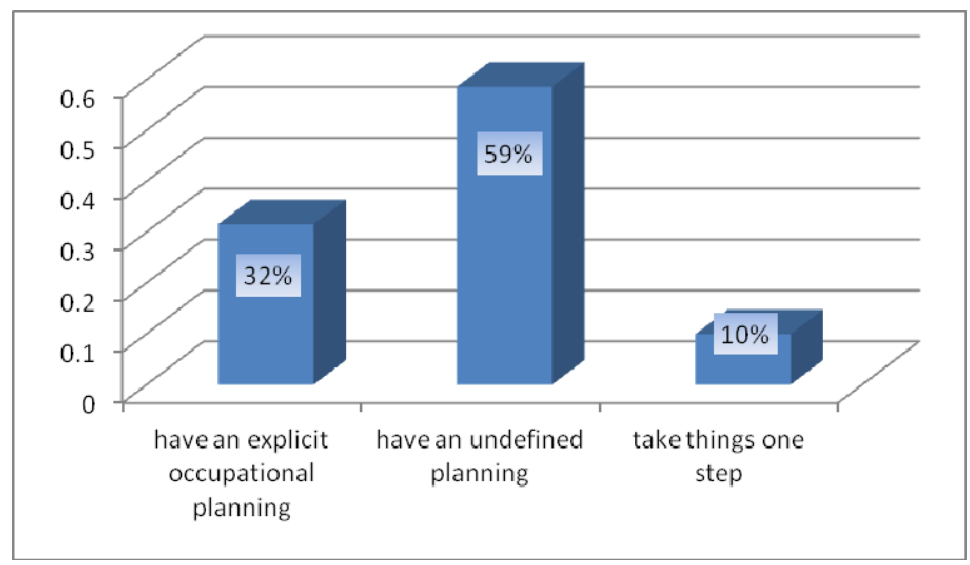

Figure 7. An analysis of the occupational planning of graduates

Thus, it can be seen that, under the circumstance when the external employment environment is not as one wishes, the graduates are generally pragmatic. They concentrate more on the current situation and most of them choose to do a perfect job. Nevertheless, they also have the plan of job-hopping and to seek for a better job opportunity. Besides, the proportion of graduates who choose to start a business is too low, which maybe is because they have no specific reference target on their path of undertaking and also their funds and experiences are limited. There are also quite a large part of graduates who prepare to pursue advanced studies to enhance their comprehensive quality and obtain more competitive strengths.

It should be noted that a large majority of students are lacking in an occupational planning, have no further reflection on how to start a successful undertaking and have no long term plan for themselves. Whether there is a systematic occupational planning is of critical significance to growth of university students. However, given the current survey condition, there are only a little bit more than $30 \%$ of graduates who have an explicit occupational planning and a large majority of graduates have an ambiguous occupational planning and even have no occupational planning, which is a quite worrisome condition and deserves our reflection. It is extremely urgent to cultivate a relatively systematic occupational planning for university students so as to let them better get established in the society and cope with the fierce market competition.

\subsection{An Analysis of Vocational Counsel and Service}

Different occupations require different occupational quality. An idea of graduates' cultivation of occupational quality and emphasis of development may help the employment counsel service more practically satisfy the requirements of university students. The survey result indicates that graduates ought to pay more attention to their capacity, and then their professional skills, and finally their character, temperament and interest, the three at the same level. Meanwhile, the survey result shows that graduates need to receive the following counseling: information acquisition capacity counseling, job-hunting skill counseling, occupational planning capacity counsel, employment capacity counsel, employment policy counsel and psychological counsel.

As is shown in Figure 8, there are 30\% of graduates who focus on cultivation and development of their capacity, there are $27 \%$ of graduates who pay attention to cultivation and development of professional skills and there are respectively $16 \%, 14 \%$ and $13 \%$ of graduates who focus on character, temperament and interest.

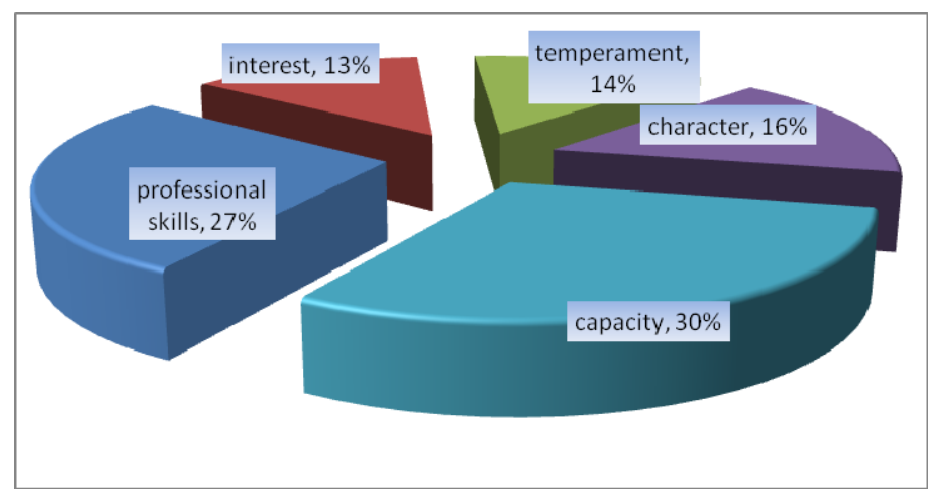

Figure 8. An analysis of vocational quality graduates pay attention to cultivating and developing 
As is shown in Figure 9, in terms of the vocational counsel that is urgently needed, the proportion of employment information, job-hunting skill and occupational planning is respectively $51 \%, 40 \%$ and $29 \%$, and then is employment capacity, employment policy and psychological counseling, which respectively accounts for a proportion of $21 \%, 16 \%$ and $20 \%$.

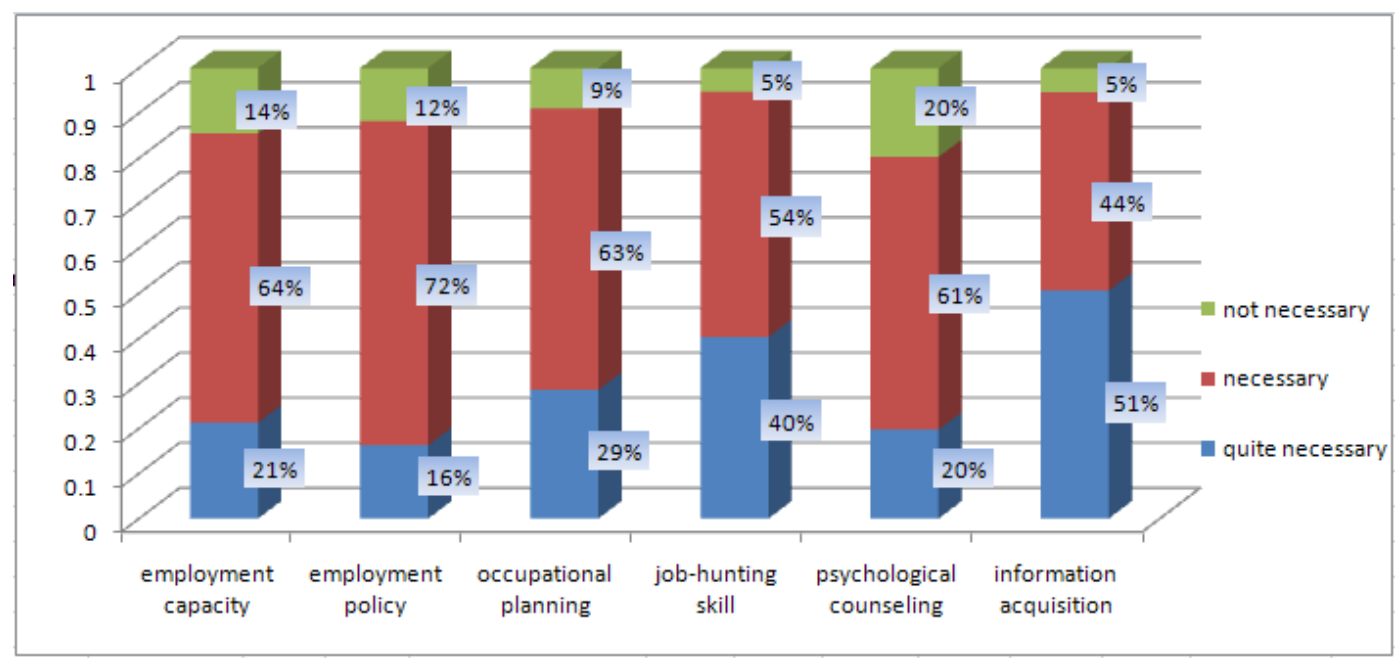

Figure 9. An analysis of guidance graduates urgently need

From the above data, it can be found that graduates concentrate most on cultivation of capacity and professional skill and they believe that this is the primary element for a successful employment. Thus, it is a focus of vocational counsel to vigorously strengthen the capacity and professional skills of university students.

It is believed by graduates that acquisition of information is the most important because they consider it closely connected with the contemporary times that is led by information and science and technology. Therefore, it has become an urgent need of university students to know about and take in the latest information of the times in due course. In that way, the universities should offer more employment information of the university students and, meanwhile, provide them with some skills in job hunting. At the same time, graduates are further required to improve their capacity of acquiring external information.

\subsection{An Analysis of Teaching and Educating}

Teaching and educating is mainly to impart knowledge structure and capacity for different professions and the degree of preference of graduates for their profession is a primary reference for efficiency of the teaching and educating. During this survey, approximately $40 \%$ of graduates show preference for their profession, and there are another half of graduates who consider their profession not too bad. In the specific teaching and educating, the graduates believe that vocational qualified certification and internship are of the greatest help to their employment, and then is social activity, professional knowledge, extracurricular activity and basic knowledge, with graduate design or graduation thesis having the smallest help to their employment.

As is shown in Figure 10, there are 37\% of graduates who show preference for their profession, $51 \%$ of graduates who show moderate preference for their profession, $10 \%$ of graduates who hardly show preference for their profession and $2 \%$ of graduates who totally show no preference for their profession. 


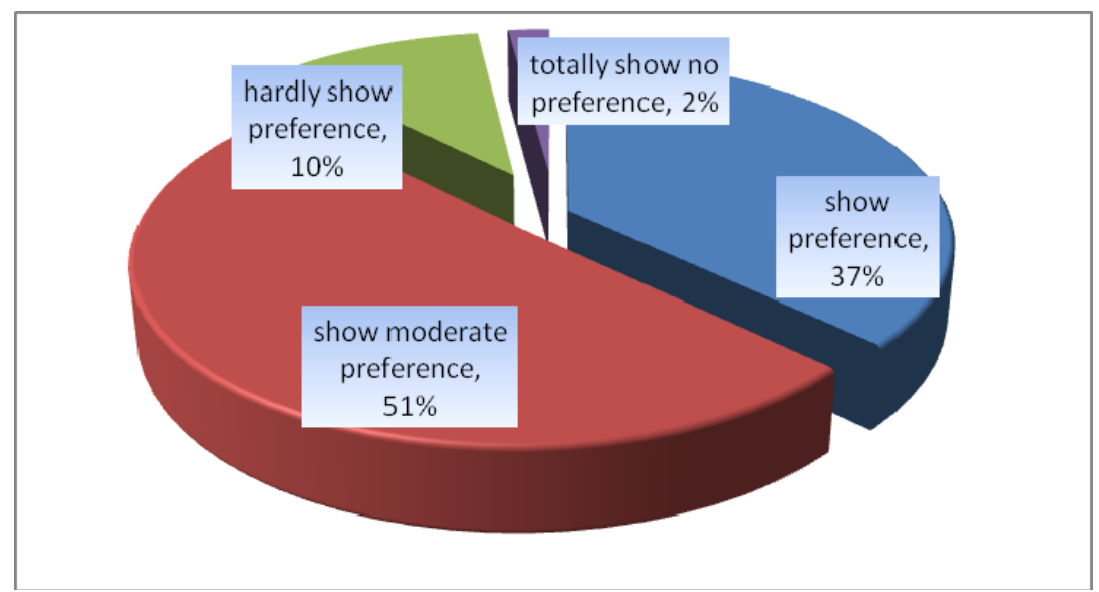

Figure 10. An analysis of preference of graduates for their profession

It is shown in Figure 11 that, there are 12\% of graduates who believe that the basic theory they have learnt in the university are of extremely great help to their job hunting, $32 \%$ of graduates who hold the view that the basic theory is very helpful to their job hunting and $50 \%$ who believe that the basic theory is of certain help to their job hunting, with a total proportion of $94 \%$. The proportion of graduates who believe that professional knowledge, internship, social activity, graduate design or thesis, extracurriculum activity and occupational qualified certification are of help to their job hunting is respectively $97 \%, 95 \%, 97 \%, 78 \%, 94 \% \& 97 \%$.

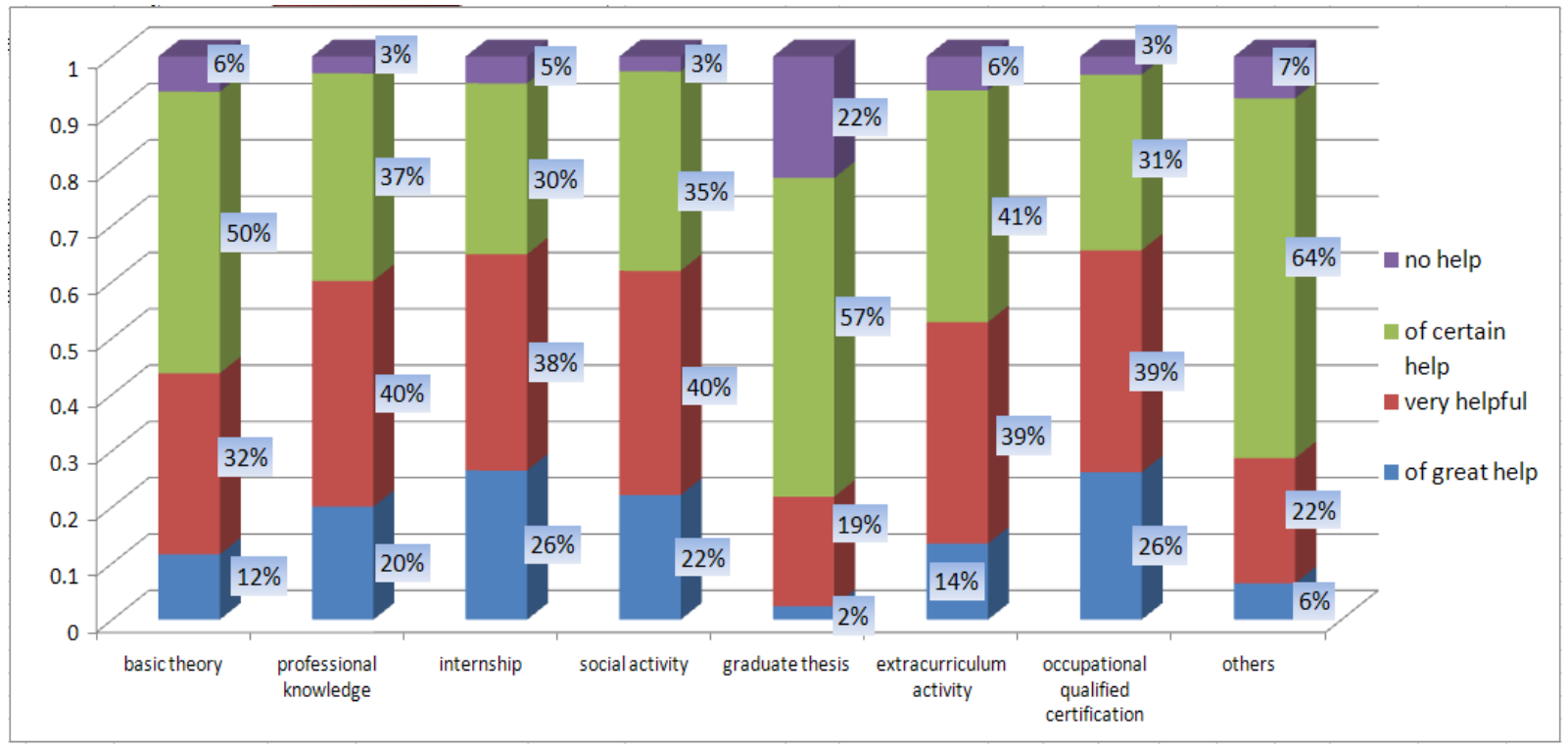

Figure 11. An analysis of help of teaching for employment of graduates

From the above statistical analysis result, it can be found that graduates take a positive attitude towards setting of their profession and the professional courses, which is helpful for successful teaching. However, there are still a proportion of $12 \%$ graduates who do not show preference for their profession. Hence, the university may conduct more professional education to let the university students find an appropriate position for themselves and select a profession that they are interested in. Meanwhile, in the eyes of the graduates, internship, occupational qualified certification and social activity in the specific teaching and educating are of the great help to their job hunting. Experience is the best teacher. Only when the knowledge in the text is applied to the practice and apply experiences concluded in the practice into the text, can we practice what we have learnt.

\subsection{An Analysis of Comprehensive Quality of Employment}

The comprehensive quality of graduates determines the quality of the job they seek for and is also a key aspect graduates and the university have to continuously improve. A large majority of graduates hold the view that our university is superior or parallel to other universities in terms of knowledge structure of basic structure, professional knowledge, computer, foreign language, humanistic knowledge and practical aspect. However, there are still a part of graduates who believe there is still a great gap. Gap in terms of English and computer is 
obvious. Most graduates evaluate their own knowledge at the level of 6-8 scores and a large majority of graduates are still at a level of passing and good.

We can conclude from Figure 12 that, compared with students in other universities in terms of knowledge structure, there are $73 \%$ of graduates who believe that the basic knowledge of graduates in our university is superior or parallel, $62 \%$ of graduates who believe that the professional knowledge of graduates in our university is superior or parallel, $59 \%$ of graduates who believe that computer of graduates in our university is superior or parallel, $56 \%$ of graduates who believe that foreign language of graduates in our university is superior or parallel, $73 \%$ of graduates who believe that humanistic knowledge of graduates in our university is superior or parallel, and $66 \%$ of graduates who believe that practical aspect of graduates in our university is superior or parallel.

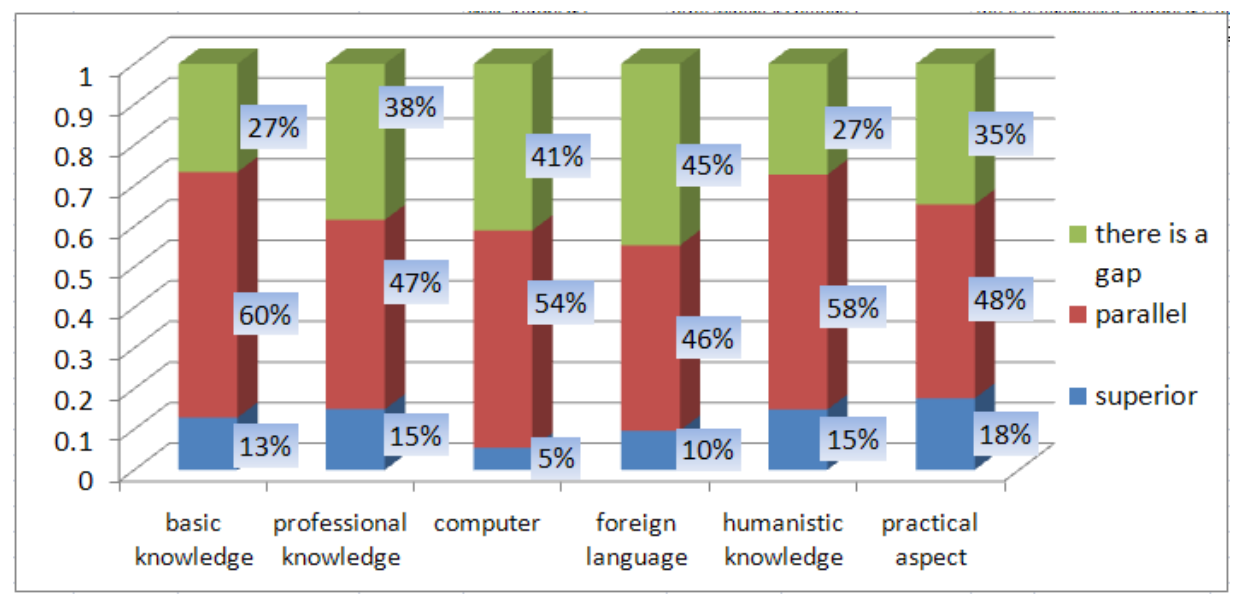

Figure 12. An analysis of the knowledge structure of graduates in our university compared with other university graduates

It can be found from Table 1 that, there are $87.9 \%$ of graduates who get an entrepreneurial spirit above 6 scores, $91.4 \%$ of graduates who get a professional dedication above 6 scores, $91.3 \%$ of graduates who get a psychological quality above 6 scores, $95.7 \%$ of graduates who get a moral quality above 6 scores, $90.8 \%$ of graduates who have a capacity of dealing with interpersonal relationship above 6 scores, $69.6 \%$ of graduates who have an innovative capacity above 6 scores, $90.9 \%$ of graduates who have an adaptability capacity above 6 scores, $83.4 \%$ of graduates who have an organization and management capacity above 6 scores, $92.5 \%$ of graduates who have a collaborative capacity above 6 scores, $79.0 \%$ of graduates who get professional knowledge above 6 scores, $67.7 \%$ of graduates who have a foreign language competence above 6 scores, $72.0 \%$ of graduates who have computer competence above 6 scores, $73.7 \%$ of graduates who have a writing competence above 6 scores, $88.2 \%$ of graduates who have a language expression competence above 6 scores, and $86.0 \%$ of graduates who have a practical operation capacity above 6 scores.

Table 1. An analysis of evaluation of graduates on their quality, capacity and knowledge structure

\begin{tabular}{|c|c|c|c|c|c|c|c|c|c|c|}
\hline Items & $\begin{array}{c}1 \\
\text { score }\end{array}$ & $\begin{array}{c}2 \\
\text { scores }\end{array}$ & $\begin{array}{c}3 \\
\text { scores }\end{array}$ & $\begin{array}{c}4 \\
\text { scores }\end{array}$ & $\begin{array}{c}5 \\
\text { scores }\end{array}$ & $\begin{array}{c}6 \\
\text { scores }\end{array}$ & $\begin{array}{c}7 \\
\text { scores }\end{array}$ & $\begin{array}{c}8 \\
\text { scores }\end{array}$ & $\begin{array}{c}9 \\
\text { scores }\end{array}$ & $\begin{array}{c}10 \\
\text { scores }\end{array}$ \\
\hline $\begin{array}{ll}\text { A. } & \text { entrepreneurial } \\
\text { spirit } & \end{array}$ & 0 & 0 & $2.2 \%$ & $1.3 \%$ & $8.7 \%$ & $10.8 \%$ & $23.4 \%$ & $27.7 \%$ & $16.5 \%$ & $9.5 \%$ \\
\hline $\begin{array}{l}\text { B. professional } \\
\text { dedication }\end{array}$ & 0 & 0 & $0.4 \%$ & $3.0 \%$ & $5.2 \%$ & $8.6 \%$ & $21.9 \%$ & $28.3 \%$ & $22.7 \%$ & $9.9 \%$ \\
\hline $\begin{array}{l}\text { C. psychological } \\
\text { quality }\end{array}$ & $0.4 \%$ & 0 & $0.9 \%$ & $0.4 \%$ & $7.0 \%$ & $12.7 \%$ & $25.8 \%$ & $28.8 \%$ & $18.8 \%$ & $5.2 \%$ \\
\hline D. moral quality & 0 & 0 & 0 & $0.9 \%$ & $3.5 \%$ & $5.2 \%$ & $18.2 \%$ & $22.5 \%$ & $32.0 \%$ & $17.7 \%$ \\
\hline $\begin{array}{l}\text { E. capacity of dealing } \\
\text { with interpersonal } \\
\text { relationship }\end{array}$ & 0 & 0 & $0.9 \%$ & $2.6 \%$ & $5.7 \%$ & $13.5 \%$ & $31.9 \%$ & $27.5 \%$ & $14.0 \%$ & $3.9 \%$ \\
\hline F. innovative capacity & $0.9 \%$ & $0.9 \%$ & $1.3 \%$ & $7.4 \%$ & $20.0 \%$ & $23.9 \%$ & $23.5 \%$ & $15.2 \%$ & $5.2 \%$ & $1.7 \%$ \\
\hline $\begin{array}{ll}\text { G. } & \text { adaptability } \\
\text { capacity } & \end{array}$ & 0 & 0 & $0.9 \%$ & $2.6 \%$ & $5.6 \%$ & $14.7 \%$ & $21.2 \%$ & $27.7 \%$ & $20.8 \%$ & $6.5 \%$ \\
\hline
\end{tabular}




\begin{tabular}{|c|c|c|c|c|c|c|c|c|c|c|}
\hline $\begin{array}{l}\text { H. organization and } \\
\text { management capacity }\end{array}$ & $0.4 \%$ & $0.9 \%$ & $0.4 \%$ & $3.5 \%$ & $11.4 \%$ & $19.2 \%$ & $28.4 \%$ & $22.7 \%$ & $10.5 \%$ & $2.6 \%$ \\
\hline $\begin{array}{l}\text { I. collaborative } \\
\text { capacity }\end{array}$ & 0 & $0.4 \%$ & $0.9 \%$ & $0.9 \%$ & $5.3 \%$ & $13.2 \%$ & $26.3 \%$ & $34.2 \%$ & $14.9 \%$ & $3.9 \%$ \\
\hline $\begin{array}{l}\text { J. professional } \\
\text { knowledge }\end{array}$ & $0.9 \%$ & $0.4 \%$ & $1.3 \%$ & $4.3 \%$ & $14.2 \%$ & $27.0 \%$ & $25.3 \%$ & $17.6 \%$ & $8.2 \%$ & $0.9 \%$ \\
\hline $\begin{array}{l}\mathrm{K} \text {. foreign language } \\
\text { competence }\end{array}$ & $1.3 \%$ & $1.3 \%$ & $2.2 \%$ & $8.3 \%$ & $19.2 \%$ & $22.7 \%$ & $26.6 \%$ & $10.0 \%$ & $7.0 \%$ & $1.3 \%$ \\
\hline $\begin{array}{l}\text { L. computer } \\
\text { competence }\end{array}$ & $0.9 \%$ & $0.9 \%$ & $2.2 \%$ & $7.6 \%$ & $16.4 \%$ & $28.9 \%$ & $22.7 \%$ & $14.7 \%$ & $4.4 \%$ & $1.3 \%$ \\
\hline $\begin{array}{l}\text { M. writing } \\
\text { competence }\end{array}$ & $0.4 \%$ & $0.4 \%$ & $3.9 \%$ & $3.0 \%$ & $18.5 \%$ & $29.3 \%$ & $20.3 \%$ & $18.1 \%$ & $4.7 \%$ & $1.3 \%$ \\
\hline $\begin{array}{l}\mathrm{N} . \quad \text { language } \\
\text { expression } \\
\text { competence }\end{array}$ & 0 & $0.9 \%$ & $1.3 \%$ & $3.1 \%$ & $6.6 \%$ & $15.3 \%$ & $30.6 \%$ & $28.4 \%$ & $10.9 \%$ & $3.1 \%$ \\
\hline $\begin{array}{l}\text { O. practical operation } \\
\text { capacity }\end{array}$ & 0 & $0.4 \%$ & $1.3 \%$ & $3.5 \%$ & $8.7 \%$ & $12.7 \%$ & $24.0 \%$ & $24.5 \%$ & $18.3 \%$ & $6.6 \%$ \\
\hline
\end{tabular}

It can be seen from Table 1 that, graduates generally have high evaluation on their comprehensive quality and low evaluation on their knowledge and capacity. Thus, their professional knowledge and practical level are still open for further improvement and they still have a way to go compared with graduates from other university graduates in terms of computer and foreign language competence. This indicates that we ought to strengthen cultivation of students' knowledge and capacity in the education and teaching process in the future so as to enhance the comprehensive quality of graduates and respond to the fierce employment competition.

\section{Countermeasures}

1) It is necessary to strengthen cultivation on students' occupational planning, guide students to make a systematic occupational planning, fully know about themselves and make clear the direction of employment.

2) It is necessary to guide students to participate in more internship and social practice to enhance students' problem resolving capacity and practical operational capacity and provide them with more internship opportunities.

3) It is necessary to set up more platforms, provide students with more relevant employment information, and strengthen their education in terms of the employment situation, employment policy and job hunting skills.

4) It is necessary to broaden students' scope of knowledge and enhance their professional knowledge and capacity as well as their foreign language competence, computer competence, writing competence and innovative capacity. 